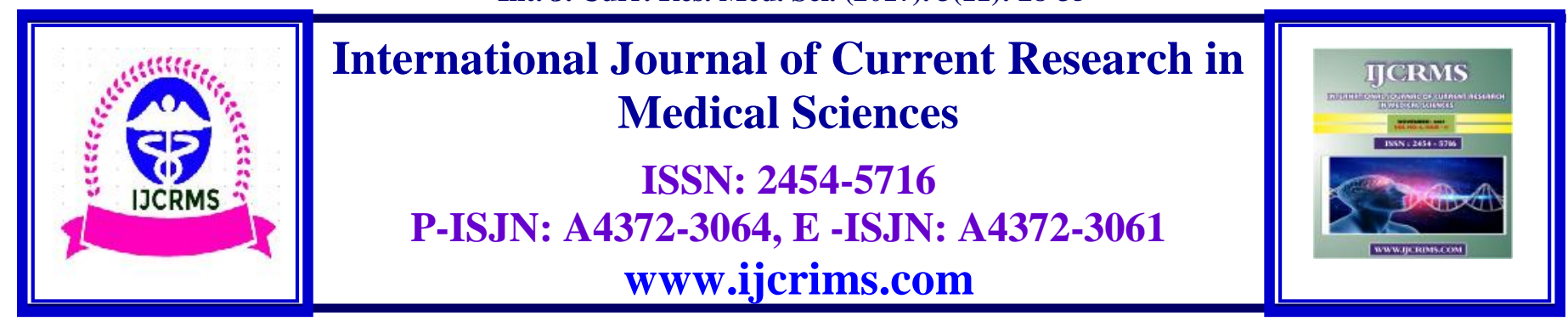

\title{
To Study the Association of Coronary Artery Disease and Non Alcoholic Fatty Liver Disease
}

\author{
Gurinderbir Singh,**Parminder Singh,***Dr. Mohit Manav, ****Malia Gupta \\ *Associate Professor, Department of Radiodiagnosis, Government Medical College, Amritsar \\ ** Assistant Professor,Dept. of Medicine , Shri Guru Ramdass Institute of Medical Sciences \& Research, \\ Vallah, Amritsar, Punjab (India) \\ ***Medical Officer, VVIP Team to Chief Minister Punjab, Chandigarh \& Ex Junior Resident, \\ Dept. of Medicine, Government Medical College, Amritsar, Punjab \\ ****Medical Officer, SHC Pogan, Distt Mohali, Punjab \\ Corresponding Author: Dr. Parminder Singh, Assistant Professor, Dept. of Medicine, \\ Shri Guru Ramdass Institute of Medical Sciences \&Research, Vallah,, Amritsar, Punjab (India) \\ E-mail: docpammy9732@yahoo.com
}

\begin{abstract}
Background: Coronary artery disease (CAD) is one of the most common and devastating illness. Non alcoholic fatty liver disease (NAFLD) is well linked with metabolic syndrome and so is coronary artery disease. But CAD has been poorly linked to NAFLD in the past. Here we conducted a study to find the association of CAD and NAFLD. Risk factors of NAFLD and CAD like hypertension, diabetes mellitus, dyslipidemia and obesity were also studied.

Subject and method: It was a case control study conducted in Guru Nanak Dev Hospital attached to Government Medical College, Amritsar. Subjects were 100 diagnosed cases of CAD with age and sex matched non CAD controls.

Results: 42 subjects in case group were having fatty liver on ultrasound in comparison to16 in controls. The mean BMI in case group was $23.85 \pm 2.11 \mathrm{~kg} / \mathrm{m}^{2}$ and in control group, it was $21.78 \pm 1.92 \mathrm{~kg} / \mathrm{m}^{2}$. The subjects labeled obese (BMI> $25 \mathrm{~kg} / \mathrm{m}^{2}$ were 39 in case group and 8 in control group (p value <0.001). Smoking was significantly higher in case group (23\%) versus control group (11\%), (p value <0.001). Hypertension was higher among cases $(43 \%)$ than controls $(12 \%)$, (p value $<0.001)$. Similarly diabetes mellitus was also high among cases $(40 \%)$ than controls $(16 \%)$, (p value <0.001).

Conclusion: In this study we observed that there is association of CAD to NAFLD. It was also observed that smoking, hypertension, diabetes, dyslipidemia and obesity are associated to CAD.
\end{abstract}

Keywords: CAD, NAFLD, BMI, Hypertension, dyslipidemia and obesity . 


\section{Introduction}

Prevalence of nonalcoholic fatty liver disease (NAFLD) is increasing in Indian population. The aim of this study is the investigation of association between nonalcoholic fatty liverdisease (NAFLD) and coronary artery disease (CAD).Coronary artery disease is a leading cause of death worldwide. Its association with metabolic syndrome is well studied. Non alcoholic fatty liver disease (NAFLD) is also associated with metabolic syndrome and both predispose to increased risk of CAD. Association of NAFLD and CAD has not been well studied in the past. We planned this study to compare the association between NAFLD and CAD. Risk factors of NAFLD and CAD like hypertension, diabetes mellitus, dyslipidemia and obesity were also studied.

\section{Aims and objectives}

1. To study the association of coronary artery disease and nonalcoholic fatty liver disease.

2. To study the occurrence of NAFLD in CAD patients and to compare occurrence in age and sex matched controls.

3. To study the association of main risk factors (hypertension, diabetes mellitus, dyslipidemia and obesity) among cases and controls.

\section{Materials and Methods}

Study Design: Cross-sectional study.

Subjects: 100 diagnosed cases of CAD with age and sex matched non CAD controls.

A case control study was carried out in the Department of Medicine and Department of Radiodiagnosis and imaging at Guru Nanak Dev Hospital attached to Government Medical College, Amritsar from Jan 2014 to March 2015.

100 cases presenting to medical emergency, medical OPD and those admitted in various medical wards in the age group of 30-70 years with diagnosis of $\mathrm{CAD}$ who qualified the inclusion criteria formed the case group. The control group consisted of equal number of age and sex matched subjects without any evidence of overt $\mathrm{CAD}$ and qualifying the exclusion criteria.

\section{Inclusion Criteria}

1. Old diagnosed cases of coronary artery disease

2. New ST segment elevation myocardial infarction (STEMI).

3. Non ST elevation myocardial infarction (NSTEMI) inclusive of diagnosed cases of ACS or stable angina.

4. Age 30-70 yrs of either sex.

\section{Exclusion Criteria}

1. Chronic alcohol intake $\geq 20 \mathrm{gms} /$ day.

2. Systemic diseases like chronic liver diseases, chronic renal diseases (serum creatinine $>2 \mathrm{mg} / \mathrm{dl}$ ), tuberculosis, patients of collagen vascular disease and thyroid disorders.

3. Patients of cardiovascular accidents, congestive heart failure, cardiomyopathies and significant valvular heart disease.

4. History of viral hepatitis with positivity of HBsAg and /or anti-HCV antibody and significantly deranged enzymes (AST/ALT $>5$ of normal).

5. Patients on drugs causing fatty liver changes like- amiodarone, methotrexate, tamoxifen, antiretroviral drugs (nucleoside analogues), tetracyclines, acetaminophen and corticosteroids.

\section{Methodology}

All the patients of CAD fulfilling the inclusion criteria and not a part of exclusion criteria presenting to Department of Medicine, Guru Nanak Dev Hospital, Amritsar, were taken as case group. Age and sex matched controls were enrolled according to the exclusion criteria and who did not have CAD.Ultrasound examination was done in Department of Radiodiagnosis Government Medical College Amritsar. In addition risk factors for CAD (hypertension, diabetes mellitus, obesity and dyslipidemia) were also studied in both the groups. 
Statistical analysis: The data was tabulated and analyzed to obtain mean \pm SD and p-value. Multiple logistic regression was applied to study the association between risk factors in both groups.

\section{Observations and Results}

\section{Demographic Profile}

In both the groups male and female ratio was same and the mean age was 53.45 years in cases group and 53.43 years in controls.

\section{Anthropometric data}

The mean BMI in case group was $23.85 \pm 2.11$ $\mathrm{kg} / \mathrm{m}^{2}$ and in control group it was $21.78 \pm 1.92$ $\mathrm{kg} / \mathrm{m}^{2}$. The subjects who were overweight $\left(\mathrm{BMI}>23 \mathrm{~kg} / \mathrm{m}^{2}\right)$ were 25 in cases group and 14 in control group ( $\mathrm{p}$ value $<0.001$ ). The subjects labeled obese $\left(\mathrm{BMI}>25 \mathrm{~kg} / \mathrm{m}^{2}\right.$ were 39 in case group and 8 in control group ( $\mathrm{p}$ value < 0.001).The difference in BMI was significantly higher in case group compared to control group.

\section{Risk factor profile}

History of smoking was significantly higher in case group (23\%) versus control group (11\%), (p value <0.001). Already diagnosed cases of hypertension were higher among cases (43\%) than controls $(12 \%)$, ( $\mathrm{p}$ value $<0.001)$. History of diabetes mellitus was also high among cases $(40 \%)$ than controls $(16 \%)$, (p value $<0.001)$. (Table 1 and 2)

Table 1Risk factor profile

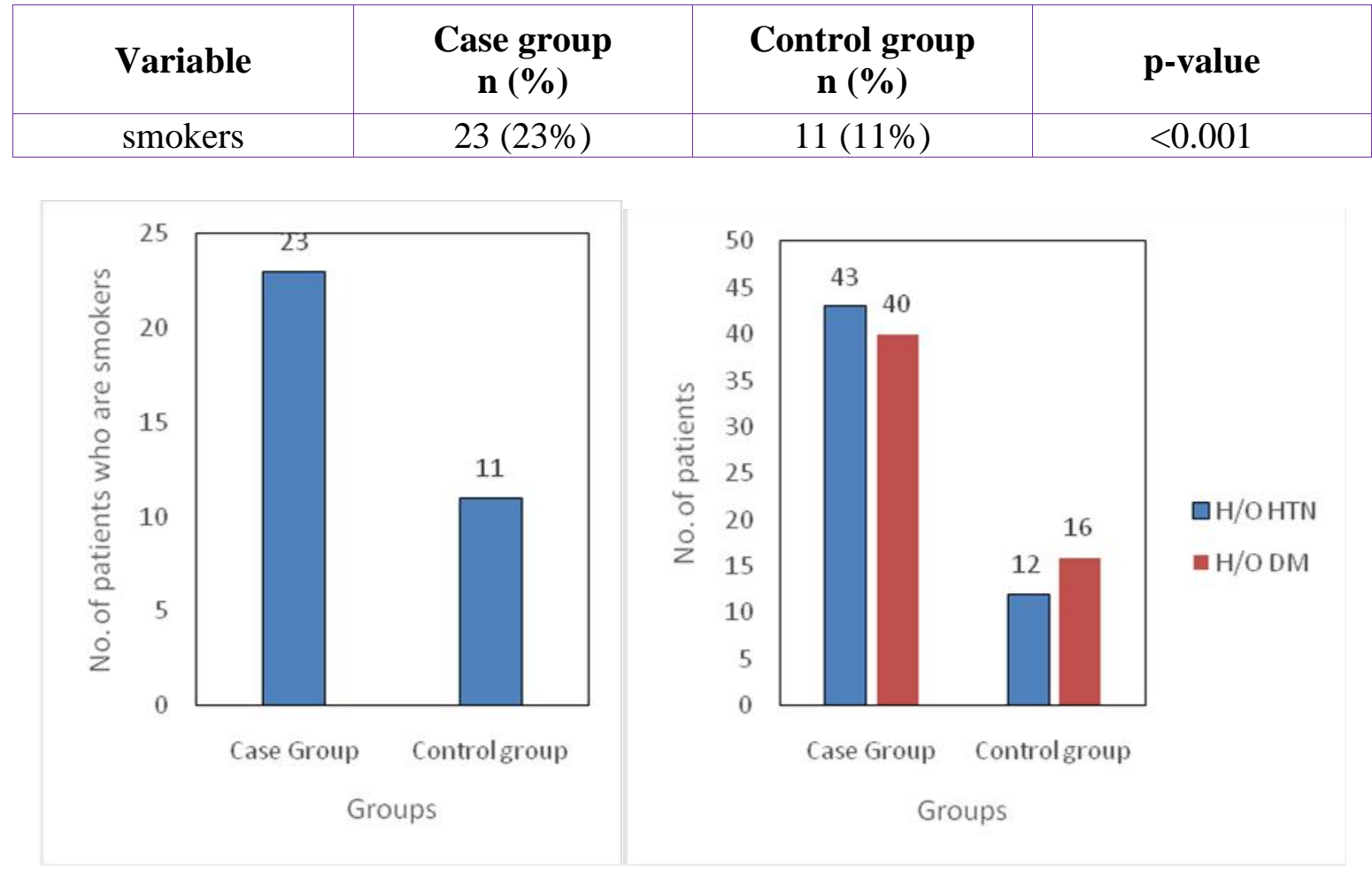

Table 2 Risk factor profile

\begin{tabular}{|c|c|c|c|}
\hline Variable & $\begin{array}{c}\text { Case group } \\
\mathbf{n}(\boldsymbol{\%})\end{array}$ & $\begin{array}{c}\text { Control group } \\
\mathbf{n}(\boldsymbol{\%})\end{array}$ & p-value \\
\hline h/o HTN & $43(43 \%)$ & $12(12 \%)$ & $<0.001$ \\
\hline h/o DM & $40(40 \%)$ & $16(16 \%)$ & $<0.001$ \\
\hline
\end{tabular}




\section{Lipid profile}

The mean serum cholesterol was $215 \pm 48.36$ $\mathrm{mg} / \mathrm{dl}$ and $163.97 \pm 31.86 \mathrm{mg} / \mathrm{dl}$ in cases and controls respectively. The cholesterol value was higher among cases than controls (p value $<0.001)$. Mean $\mathrm{TG}$ was $162.65 \pm 38.03$ $\mathrm{mg} / \mathrm{dl}$ in case group and $119 \pm 64.97 \mathrm{mg} / \mathrm{dl}$ in controls. HDL was comparable in both the groups $39.66 \pm 7.01 \mathrm{mg} / \mathrm{dl}$ and $40.22 \pm 6.44 \mathrm{mg} / \mathrm{dl}$ in cases and control groups.
Hypercholesterolemia (> 200mg/dl) was found to be $54 \%$ and $9 \%$ among cases and controls respectively ( $\mathrm{p}$ value $<0.001$ ). Low HDL (females $<50 \mathrm{mg} / \mathrm{dl}$ and $<40 \mathrm{mg} / \mathrm{dl}$ in males) was most common dyslipidemia in both the groups, $70 \%$ in cases and $69 \%$ incontrol and TG $>150 \mathrm{mg} / \mathrm{dl}$ was found in $55 \%$ of cases and 20\% of controls. Dyslipidemia was significantly higher among cases than controls. (Table 3)

Table 3 Showing number of patients with dyslipidemia in both the groups

\begin{tabular}{|c|c|c|c|}
\hline Serum lipids & Case group (\%) & Control group (\%) & p-value \\
\hline Cholesterol $>200(\mathrm{mg} / \mathrm{dl})$ & 54 & 9 & $<0.001$ \\
\hline $\mathrm{TG}>150(\mathrm{mg} / \mathrm{dl})$ & 55 & 20 & $<0.001$ \\
\hline $\begin{array}{c}\text { HDL } \\
\&<50(\mathrm{mg} / \mathrm{dl}) \text { in females }\end{array}$ & 70 & 69 & $>0.05(\mathrm{NS})$ \\
\hline
\end{tabular}

\section{Fatty liver on USG}

42 subjects in case group were having fatty liver on ultrasound in comparison to16 in controls.
Fatty liver was found to be more common in case than control group.

Table 4 Showing number of subjects with fatty liver on USG

\begin{tabular}{|c|c|c|c|}
\hline Variable & Case group (\%) & Control group (\%) & p-value \\
\hline $\begin{array}{c}\text { Total no. of subjects } \\
\text { with fatty liver }\end{array}$ & 42 & 16 & $<0.001$ \\
\hline
\end{tabular}

\section{Anthropometric data of subjects having NAFLD}

Among cases 42 subgroup of subjects had NAFLD. This subgroup of patients $23.80 \%$ $(n=10)$ were overweight and $76.19 \%(n=32)$ was obese. None of the subjects had normal weight. Among 16 controls who had fatty liver, $37.50 \%$ $(n=6)$ and $50 \% \quad(n=8)$ were found to be overweight and obese respectively. Cases with NAFLD were more obese than controls.

\section{Lipid profile of patients having NAFLD}

The subgroup of subjects having fatty liver shows that mean cholesterol was higher $(216 \pm 51.44$ $\mathrm{mg} / \mathrm{dl})$ in case group than control group (174 \pm $45.50 \mathrm{mg} / \mathrm{dl}$ ). Mean HDL was comparable in both the groups, $38.78 \pm 6.91 \mathrm{mg} / \mathrm{dl}$ in cases and $39 \pm$
$4.61 \mathrm{mg} / \mathrm{dl}$ in control sub group. Mean triglyceride level was higher in case subgroup $(180.57 \pm 31.94 \mathrm{mg} / \mathrm{dl})$ than control subgroup $(157 \pm 60.59 \mathrm{mg} / \mathrm{dl})$. The total cholesterol and TG were statistically high in the subgroup of NAFLD cases than control ( $p$ value $<0.001$ ).

\section{Risk factors predisposing to NAFLD}

On analysis of subjects having NAFLD in both the groups taken together, it was seen that Mean BMI was $25.34 \pm 1.25 \mathrm{~kg} / \mathrm{m}^{2}$ and $21.78 \pm 1.71$ $\mathrm{kg} / \mathrm{m}^{2}$ in subjects with NAFLD and subjects without NAFLD respectively. Mean cholesterol was $204 \pm 52.58 \mathrm{mg} / \mathrm{dl}$ and $183 \pm 44.97 \mathrm{mg} / \mathrm{dl}$ in subjects with NAFLD and without NAFLD respectively. Mean TG was $174 \pm 42.50 \mathrm{mg} / \mathrm{dl}$ and $127 \pm 57.16 \mathrm{mg} / \mathrm{dl}$ in subjects with NAFLD and subjects without NAFLD respectively. 
HDL was $38.98 \pm 6.33 \mathrm{mg} / \mathrm{dl}$ and $40.33 \pm 6.33$ $\mathrm{mg} / \mathrm{dl}$ in subjects with NAFLD and subjects without NAFLD respectively.

The subjects with higher BMI OF $>23 \mathrm{~kg} / \mathrm{m}^{2}$ were $94.82 \%$ and $21.83 \%$ in subgroup of NAFLD and without fatty liver respectively. History of diabetes mellitus was found in $39.65 \%$ and $23.94 \%$ in subjects with NAFLD and in subjects without NAFLD respectively. The subjects with serum cholesterol $>200 \mathrm{mg} / \mathrm{dl}$ were $48.27 \%$ and $25.35 \%$ in subjects with NAFLD and without fatty liver respectively. Subjects with TGR $>150 \mathrm{mg} / \mathrm{dl}$ were $67.24 \%$ and $27.46 \%$ in subgroup of NAFLD and without fatty liver respectively.

\section{Association of CAD and NAFLD}

In 100 cases of CAD, 42 had NAFLD. However among controls only 16 had NAFLD. The NAFLD was found to be higher among the cases of CAD than without CAD ( $p$ value $<0.001$ ). So it could be well said that NAFLD is associated with CAD, because of increased occurrence of it in CAD patients.

\section{Risk factors predisposing to CAD studied using logistic regression}

Risk factors predisposing to CAD were smoking, history of diabetes mellitus, history of hypertension, BMI and dyslipidemia using logistic regression analysis. (Table 5)

\section{Table 5 Risk factors predisposing to CAD}

\begin{tabular}{|c|c|c|}
\hline Risk factors & p-value & Odds ratio \\
\hline Smoking & $<0.001$ & 5.67 \\
\hline BMI $\left(>23 \mathrm{~kg} / \mathrm{m}^{2}\right)$ & $<0.001$ & 6.78 \\
\hline Serum Cholesterol $(>200 \mathrm{mg} / \mathrm{dl})$ & $<0.001$ & 11.74 \\
\hline TG $(>150 \mathrm{mg} / \mathrm{dl})$ & $<0.001$ & 10.87 \\
\hline Diabetes & $<0.001$ & 9.87 \\
\hline Hypertension & $<0.001$ & 7.65 \\
\hline
\end{tabular}

Risk factors predisposing to NAFLD were higher BMI, dyslipidemia, diabetes but the factors which were found to be associated to NAFLD were higher BMI, raised serum cholesterol and triglyceride ( $\mathrm{p}$ value for other factors were insignificant). Higher BMI was the most important factor which predisposes to NAFLD.

\section{Discussion}

NAFLD was earlier considered to be a benign disease but studies have shown its increasing prevalence and its association with coronary artery disease and subclinical atherosclerosis. Multicentric studies have shown that risk factors which predispose to CAD, predispose to NAFLD also. We planned to study the association of CAD with NAFLD.

The history of hypertension was $43 \%$ in case group and $12 \%$ in control group. History of diabetes was $40 \%$ in case group and $16 \%$ in control group, the association of hypertension and diabetes with CAD has been well studied. Tewari et $\mathrm{al}^{1}$ showed that diabetes predisposes to premature coronary artery disease. Diabetes is a known conventional risk factor for $\mathrm{CAD}$ as mentioned by Goel et al. ${ }^{2}$

Smoking was major risk factor being present in $23 \%$ and $11 \%$ of cases and controls. Smoking is already known to be dominant conventional risk factor for CAD. ${ }^{3}$ Obesity was more prevalent in CAD group compared to controls. In our study it was found that $25 \%$ and $39 \%$ were overweight and obese among cases compared to $14 \%$ overweight and $8 \%$ obese in control group. Obesity increases the risk of CAD. This is in consonance with previous studies done on CAD patients. $^{4}$ 
As regards the issue of dyslipidemia, elevated cholesterol was seen in $54 \%$ of cases and $9 \%$ of controls. Prevalence of hypertriglyceridemia was $55 \%$ in case group and only $20 \%$ in control group. Raised TG increases risk of CAD.

Fatty liver was diagnosed on the basis of USG. It is characterized by increased echotexture of liver compared to kidney, attenuation of USG beams and blurring of liver margins. ${ }^{5-7}$ In current study $42 \%$ and $16 \%$ of cases and controls respectively had fatty liver. Previous studies have shown that prevalence of NAFLD in normal population is around 20-30\% which increases with diabetes and CAD to around $60-70 \%{ }^{8}$. Sombat et $\mathrm{al}^{9}$ showed that NAFLD is strongly associated with CAD.

In subgroup of subjects with fatty liver, obesity was found in $76.19 \%$ and $50 \%$ in subgroup with fatty liver among cases and controls respectively. This is in accordance with previous studies which have shown that increasing BMI predisposes to NAFLD. ${ }^{10}$

Similarly dyslipidemia in the form of serum cholesterol $2200 \mathrm{mg} / \mathrm{dl}$ was found in $57 \%$ and $25 \%$, cases and controls subgroup with fatty liver respectively. Higher TG $\geq 150 \mathrm{mg} / \mathrm{dl}$ was seen in $71.42 \%$ among cases and $50 \%$ in control subgroup having fatty liver. Low HDL was $69 \%$ among cases and $87 \%$ among controls. This is also in accordance with previous studies showing raised serum cholesterol and raised TG among fatty liver subgroup. ${ }^{11}$

In the subgroup of subjects with fatty liver we observed that diabetes mellitus was seen in $42.85 \%$ and $31.25 \%$ in case and control subgroup with fatty liver respectively. This is in accordance with studies done so far, showing diabetes is associated with NAFLD. ${ }^{12}$

In this study, we observed that risk factors predisposing to NAFLD were higher BMI and dyslipidemia. Studies done so far also show similar risk factors. ${ }^{13-14}$ Obesity prevalence in patients with NAFLD varies from 30\% -100\% and prevalence of hyperlipidemia varies from $20 \%-90 \%$. In our study, we found higher BMI $>23$ $\mathrm{kg} / \mathrm{m}^{2}$ in $94.82 \%$.subjects, Dyslipidemia was found in $67.24 \%$ subjects due to raised $\mathrm{TG}$, in $77.5 \%$ due to low HDL and in $48.27 \%$ subjects due to raised cholesterol in subjects of NAFLD in both the groups. Previous studies have also shown that NAFLD is a risk factor for atherosclerosis and CAD. We have also found that NAFLD was seen more in patients of CAD. Thus it can be said that NAFLD is associated with CAD

\section{Summary}

The present study was done to evaluate the association of CAD with NAFLD. This was a case- control and age- sex matched cross sectional study which included 100 subjects of CAD and equal number of non-CAD. The age of the subjects varied from 30 years to 70 years.

- Presence of obesity was significantly higher in case group. Among cases we observed that $25 \%$ and $39 \%$ were overweight and obese respectively. However $14 \%$ and $8 \%$ were overweight and obese respectively in control group.

- Smoking was most prevalent in case group. In our study we observed that $23 \%$ and $11 \%$ were smokers in case and control group respectively.

- Among cases $40 \%$ patients were diabetic. However among controls $16 \%$ were diabetic.

- Low HDL cholesterol was observed as the most prevalent component of dyslipidemia being present in $70 \%$ of cases and in $69 \%$ of control group

- The mean total cholesterol was higher in case group than controls. Elevated total cholesterol (>200 mg/dl) was found in $54 \%$ patients of case group and $9 \%$ in control group. Hypercholesterolemia was found more in CAD group.

- Elevated triglyceride (>150 mg/dl) was present in $55 \%$ of cases and $20 \%$ of control group. Triglycerides were higher in patients having fatty liver. The mean TGR was higher in case group compared to controls.

- In case group, $42 \%$ of patients had fatty liver. However only $16 \%$ of the subjects in the control group had fatty liver. 
- Fatty liver was significantly associated with obesity and dyslipidemia and both of these increased the risk of NAFLD.

- Risk factors for CAD were smoking, higher BMI, raised triglyceride, raised serum cholesterol, diabetes and hypertension.

- In present study NAFLD was found to be associated to cases of CAD

\section{Conclusion}

In the case control, cross sectional and age sex matched study we observed that there is association of CAD to NAFLD. It was also observed that smoking, hypertension, diabetes, dyslipidemia and obesity are associated with CAD.

The subjects having NAFLD were found to have higher BMI, total cholesterol, and TG. The obesity, diabetes and dyslipidemia were associated to NAFLD.

It is time to reflect and stop eating fat containing and fried fast foods to avoid NAFLD and to save our vital and precious hearts from CAD.

\section{Source of funding: Nil}

Conflict of interest: None declared

\section{References}

1. Tewari S, Kumar S, Kapoor A, et al. Premature coronary artery disease in north India: and angiography study of 1971 patients. Indian Heart J 2005; 57: 311-8.

2. Goel PK, bharti BB, Pandey CM, et al. A tertiary care hospital based study of conventional risk factors including lipid profile in proven coronary artery disease. Indian Heart J 2003; 55: 234-240.
3. Paris P, Fay MP, Yusuf F. Increased risk of acute myocardial infarction associated with beedi and cigarette smoking in Indians. Indian Heart J 2001; 53: 731-4.

4. Yildirim N, Arat N, Dogan MS, et al. Comparison of traditional risk factors, natural history and angiographic findings between coronary heart disease patients with age $<40$ and age $>40$ years old. Anadolu Kardiyol Derg 2007; 7: 124-7.

5. El-Hassan AY, Ibrahim EM, Al Molhim FA, et al. Fatty infilteration of the liver.

6. Executive Summary of Third Report of the National Cholesterol Education Program (NCEP) Expert Patnel on Detection, Evaluation, and treatment of High blood Cholesterol in Adults (Adult Treatment Panel III). Expert Patnel on Detection, Evaluation, and treatment of High blood Cholesterol in Adults JAMA 2001; 285: 2486-97.

7. Targher G. Nonalcoholic fatty liver disease, the metabolic syndrome and the risk of cardiovascular disease: the plot thickens. Diabet Med 2007; 24: 1-6.

8. Targher G, Day CP, Bonora E. Risk of cardiovascular disease in patients with nonalcoholic fatty liver disease. $\mathrm{N}$ Engl $\mathrm{J}$ Med 2010; 363: 1341-50

9. Treeprasertsuk S, Jimenez LF, Lindor KD, et al. Review article on NAFLD and CAD. Dig Dis Sci 2010; 56: 35-45.

10. Wanless IR, Lentz JS. Fatty liver hepatitis (steatohepatitis) and obesity: an autopsy study with analysis of risk factors. Hepatology 1990; 12: 1106-1110

11. Assy N, Kaita K, Mymin D, et al. Fatty infilteration of liver in hyperlipidemic patients. Dig Dis Sci 2000; 45: 1929-34

12. Fong DG, Nehra V, Linder $K$, et al. Metabolic and nutritional considerations in nonalcoholic fatty liver. Hepatology 2000; 32: 3-10 
Int. J. Curr. Res. Med. Sci. (2017). 3(11): 28-35

13. Ludwig J, Viggiano TR, Mc Gill DB, et al. Nonalcoholic steatohepatitis Mayo Clinic experience with hitherto unnamed disease. Mayo Clin Proc 1980; 55: 434-8

14. ItohS, Yougel T, Kawagoe K. Comparison between nonalcoholic steatohepatitis and alcoholic hepatitis. Am J Gasteoenterol 1987; 82: 650- 4

\begin{tabular}{|c|c|}
\hline \multicolumn{2}{|c|}{ Access this Article in Online } \\
\hline \multirow{2}{*}{ 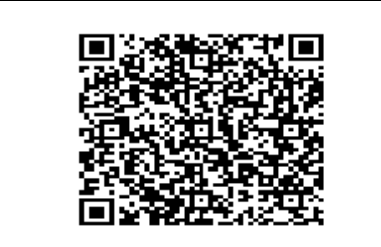 } & $\begin{array}{l}\text { Website: } \\
\text { www.ijcrims.com }\end{array}$ \\
\hline & \multirow[t]{2}{*}{$\begin{array}{l}\text { Subject: } \\
\text { Medical Sciences }\end{array}$} \\
\hline Quick Response Code & \\
\hline
\end{tabular}

How to cite this article:

Gurinderbir Singh, Parminder Singh, Mohit Manav, Malia Gupta. (2017). To Study the Association of Coronary Artery Disease and Non Alcoholic Fatty Liver Disease. Int. J. Curr. Res. Med. Sci. 3(11): 2835.

DOI: http://dx.doi.org/10.22192/ijcrms.2017.03.11.007 